\title{
Inform with care: ethics and information in care for people with dementia
}

\section{Marian Barnes and Flis Henwood}

\section{Abstract}

Good care is often positioned as a natural by-product of the widespread availability of good information ('inform to care'). This paper contests this association through empirical investigation of the information-care relationship in the context of dementia care. It combines critiques of the 'informatisation' of care with insights from the epistemological dimension of care ethics to argue that information is better understood as 'situated knowledge' and that the relational practices of care involve the mobilisation and negotiation of different types of knowledge that are specific to caring relationships and contexts. The argument is illustrated through the three cases of caring relationships taken from a qualitative evaluation of an information and support course for carers of people with dementia. These cases highlight the specificity of caring relationships and the very different consequences of introducing new forms of knowledge into each relationship and provide evidence for the need for a paradigm shift where the idea of informing to care is replaced by a process of informing with care. In the former, information is understood as separate and outside of care, while nevertheless acting upon it to produce care; in the latter, information is understood as inextricably linked to care (with care) but not in any predetermined or uni-directional sense. The paper identifies key interlinked components of the 'inform with care' approach derived from the cases discussed.

\section{Introduction}

As far back as Information for Health (NHS Executive 1998), information policy from the Department of Health in England has made grand promises about the potential of information to transform health care in favour of patients. Information for Health spoke of 'harnessing' the 'information revolution' to 'benefit patients' (NHS Executive 1998, 5) and the latest Department of Health 
(England) information strategy (Department of Health 2012a) continues this theme. Information also figures prominently in the Public Health White Paper Healthy lives, healthy people: our strategy for public health in England (Department of Health 2010) which talks of the need to "harness the information revolution to make the best use of evidence and evaluation and support innovative approaches to behaviour change throughout society' (no page number). Similarly, the Social Care White paper: Caring for our future (Department of Health 2012b) places heavy emphasis on the importance of good information in the provision of improved care and commits $£ 32.5$ million to a new website with information on care and support and talks of the 'power of information' to 'drive more integrated care'(12).

While the emphasis of these policy documents differs slightly, all share a belief in the transformative power of information, with good care being positioned as a natural by-product of the widespread availability of good information. In this paper, we address these assumptions through empirical investigation of the information-care relationship in the context of dementia care, where, in line with this 'information to care'-type thinking, the Dementia Strategy for England (Department of Health 2009) emphasises the objective of enabling better information. Drawing on a study of family carers' experiences of undertaking an information course designed precisely to support their caring relationships (arguably, then, supporting them in delivering 'better care'), we explore the relationship between information and care and explicate the sometimes complex relationship between the two. We start by exploring the contested nature of both 'information' and 'care' and setting out our theoretical approach which understands information as 'situated knowledge' and care as ethical practice. We then examine three cases of care relationships drawn from an evaluation of the Alzheimer's Society's 'Carers' Information and Support Programme (CrISP)' (undertaken in the UK in 2012-13) in order to develop a more situated and relational account of the relationship between information and care and propose a new approach to practice that involves informing with care rather than to care. 


\section{The informatisation of care}

A growing body of work developing critical perspectives on the information paradigm in health and social care draws attention to the way in which care is being marginalised by information. Spoel (2006) in a study of informed choice in a midwifery context, argues that the dominance of the consumerist model of information provision to 'empower' women to make 'autonomous' choices risked creating situations in which information was replacing care. Salander and Moynihan (2010, 119) show how the 'instrumental intervention' of 'information giving' that dominates the new approach to cancer care fails to address the fact that 'healing' is a 'contextual experience'. Salander and Henriksson (2005) argue that the delivery of information may be less important to patients than expressions of care, and Sinding et al $(2010,1099)$ show how women's attempts to 'deflect and reframe' responsibility for decision-making and to elicit physicians' opinions in the context of breast cancer, can be read as resistance to the rational information paradigm that dominates the current organisation of cancer care. In a study of information aimed at encouraging self-care in the field of 'healthy living', Author et al (2011) draw explicitly on Mol's logics of choice and care (Mol 2008) to make sense of the resistance to healthy living messaging they encountered amongst participants. They argue that calls for more collective forms of responsibility, rejection of the 'facts' of overweight and obesity in favour of more situated and embodied understandings of healthy weights, and accounts of 'good' or 'useful' information resources that highlight the importance of local social networks, can be understood as forms of resistance to the logic of choice and as attempts to articulate an alternative 'logic of care' (Mol 2008). From this perspective, healthy living and the (self) care practices involved cannot be reduced to an individualised, rational process of informationseeking and choices resulting in improved health outcomes. Rather, these practices manifest as messier, emotional and uneasy processes often involving uncertainty, anxiety and self-doubt, along with a need for interdependence between others with shared experiences, and support and expressions of kindness from help/service providers (Author et al 2011). 
A related body of literature in medical sociology has examined how 'expert' or professional knowledge, often now packaged as the more neutral 'health information' (Nettleton 2004, 673) is held up as superior to other forms of knowledge and is often resisted by patients and carers for failing to take account of knowledge based in the patient experience. A parallel set of arguments exists in the literature on, and from within, service user movements, drawing attention to the importance of the experiential knowledge of those living with, for example, disability or mental illness, for understanding illness, its impacts and what helps in its treatment (e.g. Barker, Campbell and Davidson 1999). Author et al (2010) have argued that, in seeking to understand how people engage with health information, it is vital to recognise the contextual nature of information, understanding all health 'information' as forms of 'situated knowledge': views from 'somewhere', rather than 'nowhere' (Haraway 1991). In her study of telecare, Pols (2012 82) has distinguished between three different types of situational knowledge that are enacted in care practices 'propositional knowledge', such as medical knowledge about the physiology of a disease, 'knowhow', such as clinical knowledge used to improve the daily life of patients, and 'know-now', the practical and embodied knowledge of living with a disease. According to Pols, having 'know-now' is what makes it possible for patients to translate different kinds of knowledge into practically useful knowledge that enables living life with a disease. She argues that different forms and combinations of knowledge are needed at different times and that these are different yet 'interdependent' knowledges.

However, it is important not to lose sight of the way that knowledge links to power. Although the value of patient and service user experiences, as forms of knowledge, is now being recognised in diverse policy responses including those of 'Expert Patients', 'Experts by Experience' and various coproduction initiatives, this is by no means uncontentious and questions about who controls the production of knowledge and how issues relating to, for example, disability and mental illness are framed and researched, continue to be a focus for action and contention by service user movements 
(Author 2013). Understanding information as 'situated knowledge' draws attention to information as a site of political contestation concerning both whose and what knowledge is regarded as relevant and legitimate in specific care contexts. It also emphasises the significance of practices that enable experiential and professional knowledge to be negotiated amongst those giving and receiving care. In order to reflect on the complexities of caring relationships and further explore the place of information within these, we draw from work on the ethics of care.

\section{Care: affect, epistemology and ethics}

The origins of the ethics of care lie in Gilligan's (1982) distinction between judgements based in the application of abstract principles (justice ethics) and a situated, contextualised assessment of what is right in a particular situation (care ethics). Care ethics is grounded in a recognition of the relational ontology of human subjects and the necessity of care to survival and well-being (e.g. Sevenhuijsen 1998). In a recent review of care in diverse contexts, Author (2012) argued that care needs to be understood in three ways: as a way of conceptualising personal and social relations, as a set of values or moral principles, and as a practice. Tronto (1993) identifies the dimensions of care as comprising: attentiveness, responsibility, competence and responsiveness, all of which are necessary to the integrity of care. These perspectives are in marked contrast to a view of care as a commodity to be chosen and delivered, or as an oppressive practice to be resisted and replaced by the apparently more neutral notion of 'support' (Author 2011). In recognising care as a necessity for all, care ethics also unsettles the distinction between subjects identified as either 'givers' or 'receivers' of care, acknowledging that the same person can occupy both positions at the same and different times (Ward 2011).

The importance of knowledge to good care is also addressed in care ethics. For example, Kittay (2010) draws on her experiential knowledge of being the mother of a young woman with severe cognitive disabilities to challenge conclusions drawn by some moral philosophers about the moral 
worth of such people. In particular, she invokes the necessity of 'epistemic responsibility: know the subject you are using to make a philosophical point; and second, epistemic modesty: know what you don't know' (401). She argues that a failure to acknowledge what is not known is a moral failure.

The importance of the epistemological dimension to care ethics in the context of both policy making and care practices has also been argued by Author (2012). Of most direct relevance to our argument here is the role of knowledge in the context of care practices, whether these comprise the work undertaken by those in paid caring roles, or in the context of family and friendship relationships through which care is given and received. Sevenhuijsen refers to the 'knowing and thinking subject' $(1998,89)$ of feminist care ethics, and Tronto's element of 'competence' assumes that the care giver can and does draw on a range of types of knowledge to ensure competent care. Author suggests that knowledge includes: knowledge about the problems facing the care receiver and how they may impact the individual and the relationships in which they are engaged; knowledge of different forms of practice and how they might assist in the particular context being addressed; knowledge about available services and entitlements to welfare benefits that might provide practical assistance and relieve strains associated with coping with everyday life. She offers examples of where lack of knowledge and a failure to understand the impact of specific practices can result in a failure of care (pp. 77-8). In the specific context of work with people with dementia, Brannelly (2011) highlights the importance of an intimate knowledge of family relationships and history to enable good care.

But whilst those using health and social care services should expect those in paid helping roles to draw on professional knowledge and practice wisdom, recognising care as a relational practice suggests that we should not think of knowledge in use as uni-directional. Recognising the significance of the experiential knowledge of those who receive care as necessary to the process of care helps address the power imbalances that have led some to reject care; in care ethics terms we can understand such recognition as necessary for 'responsiveness' (Tronto 1993; Author 2012). We can also suggest that one aspect of the responsibility of care givers (paid and unpaid) is to learn from 
the experiential knowledge of the care receiver. Pettersen and Hem (2011) offer a rather different perspective. They suggest that 'mature care' requires that the care receiver recognise the point of view of the care worker, their relatives and other patients (the context is that of in-patient mental health services). A 'lack of cognitive flexibility', they argue, 'makes it difficult for those cared for to correct, change, nuance or expand their understanding of their own situation in the light of others' input' (221). Naming 'cognitive flexibility' as part of the process of care emphasises that we should not understand care solely in terms of affect or practice skill, but also as requiring the capacity to recognise and work with different types of information and knowledge.

Thus, care receivers need to be active participants in the process of care and this necessitates a dialogic process in which responses from the care receiver inform the practice of the person(s) caring for her/him. In the case of dementia or other cognitive impairment, such responses may be expressed non-verbally. Author (2012) has argued that Tronto's element of 'responsiveness' should be developed to encompass the way care receivers contribute experiential knowledge to the care process and that this offers a means of counteracting the danger that care ethics focuses too much on caregivers rather than care receivers.

Author (2012) also notes the affective nature of both care and information. Whilst care ethics understands care as more than a compassionate response to another, it is given and received in the context of relationships that both embody and are likely to generate difficult and conflicting emotions for care givers and receivers. Not only do these emotions constitute a key aspect of the context that impacts care, they also constitute important information about the value attached to the object of the emotion (Nussbaum 2001). Thus, for example, an angry response from a care receiver to an offer of help can inform the caregiver of the importance attached to being able to perform the relevant action alone.

Combining critiques of the informatisation of care with insights from the epistemological and affective dimensions of care ethics offers us a way of moving beyond an understanding of 
information simply as a resource for better care. Understanding all information as 'situated knowledge' enables us to recognise both the different types of knowledge necessary for good care and the power relations that are integral to the mobilisation of different knowledges in the practices of care. Care ethics, with its explicitly relational ontology, enables us not only to recognise caring as a relational practice, but to recognise the ways in which knowledge links to care. In particular we wish to emphasise here the need for epistemic responsibility and epistemic modesty (knowing the subject of care and, conversely, acknowledging what you don't know); second, the importance of cognitive flexibility required to recognise and work with different types of knowledge; and third, the importance of understanding the emotional or affective aspects of both information and care.

In the following sections, we consider three case studies that enable us to explore the situated, complex and contingent relationship between information and care in the context of family carers and dementia care. We do so in order to further define and refine an alternative paradigm for understanding and practising information-care relationships: 'inform with care'. Our cases are drawn from an analysis of data collected for an evaluation of an information and support programme run by the Alzheimer's Society (AS) for carers of people with dementia.

\section{Methods}

The 'Carers' Information and Support Programme (CrISP)' was designed 'to improve knowledge, skills and understanding for those caring for a person with dementia, by providing effective support and up-to-date, relevant and evidence-informed information' (Alzheimer's Society 2012). With two colleagues, we were commissioned to undertake an evaluation of this programme from the point of view of carers. The study, involving 25 carers in seven sites in England was undertaken between 2012 and 2013 (see Authors et al 2013). The sample was selected to include a diversity of care 
relationships including co-resident and non co-resident carers, carers in rural and urban areas, spouse and adult child carers, and male and female carers. Most of the spouse carers but only about half of the adult child carers lived with the person they cared for. Most of those caring for a parent were in their 50-60s and most caring for a spouse were in their 70-80s. Those being cared for were between 70-85, including six who were living in nursing or residential care. In five cases, the person with dementia had died before the interview took place. Interviews lasted between one and two hours and took place either in the carers' homes or in confidential spaces at local AS offices. Ethical approval was gained through the University of XXXXX Research Ethics and Governance Committee and in line with ethical procedures required by the AS.

Our perspective on the importance of understanding the significance of information in the contexts of caring relationships necessitated situating subjective responses to participating in the CrISP programme within the specific caring relationships and contexts involved. We therefore adopted the narrative interview method and invited carers to tell us about how they became a carer and how their caring relationships had developed over time, before asking more focussed questions about their responses to the CrISP programme itself. In this way, we were able to analyse their accounts in the context of their different experiences of, and responses to, caring for a relative with dementia.

Data were analysed thematically, while drawing on the narrative structure of interviews to prevent the loss of context that can accompany the thematic approach. Data were analysed manually, with initial coding of transcripts undertaken by all team members, before being shared and refined to produce the final themes presented in the full evaluation (Authors et al 2013). Key to our analysis was the importance of understanding that the carers who participated in the CrISP programme were, in this context, care receivers as well as care givers and that their experience of the context in which they were being offered information and support was key to their ability to deliver good care to their family member (see also Authors et al 2014). In this paper, we illustrate and develop this 
theme further through a series of three case studies taken from the full evaluation. The cases were deliberately chosen to reflect both contrasting experiences of taking part in the programme and contrasting caring relationships and are not, in any sense, being presented as representative of all carers' experiences. Rather, in each case, we elucidate the complex relationship between information and care to develop an empirically -driven conceptual analysis that argues for a new ethical approach to information provision ('inform with care') which is able to recognise and address the complexity, situatedness and relationality of information-care giving and receiving to move beyond the currently dominant 'inform to care' approach.

\section{Information and relational care}

\section{Colin and Mary}

Colin, aged 50 and still in full-time work, described himself and his wife as an 'odd couple.' Mary was 75 and was diagnosed with Alzheimer's disease 6 months prior to the interview. Colin had noticed changes suggesting there was a problem approximately two years previously. Colin never felt fully at ease on the course. In particular, he objected to the lack of recognition of the distinctiveness of spousal relationships in the context of living with someone with dementia, reflecting a broader reaction to the homogenising impact of official designations of 'carers' (Molyneaux et al 2011). He noted:

She's not my partner, she's my wife...Partner and spouse I don't think are quite the same thing at all. But taking those two in isolation, partner/spouse is a completely different set of emotions to siblings or to non-relative carers, a completely different set of emotions.

Later he said:

...the two ladies [the other two spouse carers in the group] got very upset quite a few times. I did but I wasn't going to admit to it at the time. And there wasn't enough - it was very 
clinical, the course...there wasn't enough emotion or care for the people you're actually dealing with.

Colin described the lack of attention to the specific emotional dimension of caring for a spouse with dementia as 'thoughtless'. His response to the course was impacted, from the start, by what he considered an excessive amount of 'administration' that he interpreted as 'backside covering'. He said all course participants were given a number and 'you're thinking, I am here to get help, I don't want to become a number and it seemed very authoritarian, very big brother...'. Although he recognised that those running the course wanted to maintain confidentiality, by making the process an impersonal one, it alienated him which, in turn, had a direct impact on his ability to engage with the information sharing aspects of the course: 'Don't treat me like a nobody because if I'm nobody then the information you're giving me is not going to gel.'

Colin resisted being identified as his wife's carer and emphasised that she was at an early stage in her dementia. He described Mary as still being able to do things, but as forgetting things, starting to repeat herself and putting things away in odd places. He saw his attendance at the course as a way of finding out things he needed to know while protecting her from the full impact and likely prognosis of her diagnosis. As the interview progressed, he acknowledged that he might be 'fooling himself' in terms of the extent to which things had changed.

Whilst rejecting the designation of 'carer', Colin did accept that he and Mary were involved in a 'caring relationship'. Indeed, it was his attempt to sustain a 'normal' caring relationship between husband and wife that was the source of his negative reaction to much of the information presented on the course: 'By the time we got to the end of the second session I felt like coming out and slashing my wrists'.

Rather than getting the help he needed, Colin felt he was being exposed to 'doom and gloom stories' about what was likely to happen and that this was much too early for him. In response to the 
interviewer's question as to whether he found it hard to take the information on board, he responded that the problem was that he did take it on board:

It was far too detailed, far too heavy, ah, it was scary, it really was scary and you think to yourself, 'there's nothing I can do about that'. Which I know there's nothing I can do about it and perhaps it's a bit 'ostrich in the sand' but you don't always want to know.

Colin's overall assessment was that it had been a 'horribly soul-destroying course'.

\section{Pauline and Francis}

Pauline's (second) husband Francis had experienced depression and anxiety for some time before he was diagnosed with dementia. He was also an alcoholic. His mother had also had mental health problems and he was very aware of, and resistant to, the stigma of being labelled mentally ill. Pauline herself was physically disabled and had previously cared for her first husband who was also disabled. Francis had committed suicide just a few months before the interview with Pauline.

Pauline's response to the CrISP course was much more positive than Colin's. As someone who had long been active in relation to disability issues and who, in her professional life, had worked in adult education, one of her first responses to Francis' diagnosis was to find out as much as she could about dementia and to register with an Alzheimer's Society Forum where carers could share information. She adopted a critical perspective on the way the course tutor put over information, suggesting there were things she would have done differently, but became more impressed with him as the course went on. She also commented on the value of receiving and sharing information in an interactive way:

when we first started, I realised that I'd already found all that before, but it was very helpful hearing it again with the other people there. I think I found the people that did the course with me as much value to me as... as what was in the course. 
Pauline went on to use the knowledge she had gained in the context of setting up a support service for others living in the supported housing complex to which she and Francis had moved.

Pauline's initial response was to understand information as a practical resource that could enable her to become more competent as a carer. Unlike other carers we interviewed, she also sought to share the information she accessed with Francis, in the belief that he too would find this helpful. However, she came to realise that what she described as her 'clinical' approach to this was not helpful because the information she gave to Francis frightened him. She located her approach to this not only in relation to her usual way of acting, but also to the way in which they had previously discussed and shared things with each other:

I don't think I dealt with Francis very well. I mean, erm... because I've always been known to be a person that researches things, and if I found something of interest I might quite unwittingly, not intentionally, say, 'Oh!' you know, 'I've got some good information here' and talk... because I would forget that he actually had dementia, and we'd always talked about things and discussed things.

Her actions in seeking out information were intended not only to help her improve her knowledge as a basis on which to care, but also to find out about services that would benefit him. But information did not necessarily result in the provision of services: 'I wanted him to have the services and we couldn't seem to find any.' And perhaps more significantly, it appeared to both contribute to his sense of despair about his illness, and to his sense of his wife being in opposition to him.

Pauline also recognised the way in which his perception of a shifting power relationship impacted her relationship with him as his carer. She contrasted this with her experience with her previous husband with whom she had shared the experience of physical disability. Talking about Francis, she said: 
he didn't like me doing it (the course). He thought that I was capitalising on his illness, because I was interested in it. (pauses) It's so different looking after somebody with an illness like his and looking after somebody with a physical illness. When I was looking after John, my first husband, he was, he was happy that I was always trying to find ways of dealing with problems of paraplegia, and we both used to read the same things and look at the same things and go to the same things. But Francis felt that I was capitalising on his illness, yeah.

Pauline reflected on the very different situations of those doing the course with her and distinguished 'what I would call [those who have] got quiet dementia' from the challenges she faced in dealing with the extent of Francis's physical as well as emotional agitation. She had come to recognise the emotional impact and consequences of information and the necessity of encompassing this in using information in order to care, but also thought that, whilst it might have helped 'if I'd been the touchy-feely sort of person and (pauses) but I wasn't and I'm not. And he knew I wasn't, and there's nothing we can do about it.'

Thus, while Pauline did think that the course had made her better equipped to care, she also recognised the limits to what information could help with: 'I couldn't get into his head, if you know what I mean. I couldn't understand how he was thinking. I don't think there's a course that would ever allow me to do that.'

\section{Lesley and Edna}

Lesley was caring for her mother. At the time of the interview, Edna had quite advanced vascular dementia and used a wheelchair to get about. A year or so before the interview, Lesley had given up employment as an adult education tutor to care for her mother and father, ill with cancer, full-time. Prior to his illness, Lesley and her father had shared Edna's care, although her father had his own mental health challenges and also needed taking care of: 
so there were lots of issues with my dad's mental health, so I was trying to not damage that, at the same time as doing the best that I could to look after my mum and, at the same time, looking after my dad, and they had very different needs...

Information was key to Lesley's ability to care for Edna, although she describes how, in the early days, prior to diagnosis, 'just coping' was her priority. Later, when her caring role became what she describes as 'more established', she started to seek out information and develop more knowledge about dementia and its progression. Lesley had been an IT tutor and described how her experience enabled her to 'pinpoint what was valid information' and 'sort of sort the wheat from the chaff'. She was concerned that others could have been left 'ill-informed or frightened by what they'd read'. She reflected on how important these skills were as she couldn't remember anyone involved in Edna's diagnosis actually pointing her in the direction of any relevant information, saying '...I don't remember anybody saying "you might find this useful". It was a case of me finding things out for myself'.

At the time Lesley undertook the course, she was still caring for both her mother and father and describes the timing of the course as 'perfect' because she was at her 'most stretched' at that time. She described feeling really stressed as her father's prognosis worsened and she began to really worry about how Edna would react to his death. She describes this as a time when she began questioning her own caring approach, asking, 'Am I doing this right?' and of the 'dawning' of the real sense of responsibility she began to feel at this point. She describes a need for reassurance when she says '...because you haven't got somebody sat next to you saying "yes, you've done a good job there" and "try this, perhaps, next time"' , conjuring up the sense support that many carers found they needed and that the course was able to offer to most. The course left Lesley feeling much more 'relaxed' about how she cares for her mum. She describes how she would never have thought herself capable of being a carer and that she had 'astounded' herself with what she' $d$ 'managed' and had begun to feel 'quite proud' of what she does. 
Lesley was very positive about the timing of the course and what she had learned from it. Lesley talked about learning new ways of being with her mother and of learning from other carers' experiences. She described herself as someone who always wants to 'go and get on and get things sorted' and, in some ways, her focus on information searching fits in with this. However, when reflecting on how the course had changed her, she describes how she had learned to 'recognise when it's not appropriate to take that style when looking after mum'. Instead, she had learned to be 'softer', 'reflective' and 'thoughtful'. She describes learning to watch and learn from observation about what might be the best way forward in terms of caring practices, a shift that we might think of as learning to be more 'attentive'. Lesley's increasing awareness of the importance of understanding information in the wider context of care is further illustrated by her responses to questions about the content of information provided on the course. She was quite circumspect about its value for her. While she did talk positively about the 'wonderful hand outs' and how she 'clung to them like gold dust', she explains how their value was determined by the extent to which they were able to convey the experiences of other carers. She describes how she valued their content 'particularly where there were quotations from other carers' experiences' and continued:

...it was very much brought into real life by examples or experiences as part of those information sheets...a professional person can write wonderful, wonderful text, but it doesn't hit home if it's not from the heart. And where other carers have given comments, you think, 'They understand'.

Later, Lesley talked about learning to think from the perspective of the person with dementia and how that helped her care for her mother in a way she felt happier with. This perspective was communicated to carers via course tutors who used images in a powerful way to help enable carers to experience the world as a person with dementia would. Like several other carers, an example of people with dementia not using a conservatory because it involved crossing a rug that they saw as a pond, was experienced by Lesley as 'revelationary'. She described how, 'from that moment', she 
began to 'view thing very differently'. This means of helping carers to identify with the person they were caring for, to experience their world, and adapt their caring practices with an awareness of this new perspective, was not 'information provision' in any conventional sense. Instead, it may be understood as a means of conveying the 'experiential knowledge' of the people with dementia to carers and, as such, as a key element in enabling understanding of how dementia impacts the way people view the world.

When asked directly what it was about the course that helped her most, Lesley described it as 'like being wrapped in cotton wool'. She talked about feeling 'valued' and 'hugely welcome' and 'very, very safe'. She also spoke about it being a space where one could say 'anything at all' and not 'shock' people and where, even where information was 'fearful', it was handled in a supportive way, as in, 'we will help you with this'.

\section{Discussion}

Our analysis of the relationship between information and care suggests the need for a paradigm shift where the idea of informing to care is replaced by a process of informing with care. No longer is information seen as separate and outside of care, while nevertheless acting upon it to 'produce' care. Instead, information is understood as inextricably linked to care (with care) but not in any predetermined or unidirectional sense. Here we draw on these three cases from the dementia family carers' information and support programme to identify key interlinked components of the proposed 'inform with care' approach.

Recognising that information can confound and undermine caring relationships as well as support and enhance them is the first important message we wish to get across here. Informing with care means being attentive to the emotional or affective aspects of information/knowledge and the ways in which new information or knowledge can destabilise as well as support caring relationships. Colin linked his 'ostrich in the sand' reaction to much of what he heard on the course to his being 'scared' 
by what he heard. This strong emotional reaction meant that he was unable to process and make use of what was being offered to support his caring relationship with his wife. Colin's impression was that this was neither acknowledged nor addressed by the course facilitator, oversights that he described as 'thoughtless' but that we might redefine as 'careless', as informing without care.

Our second point concerns what Kittay has called 'epistemic responsibility' (Kittay 2010). Our cases suggest that informing with care involves 'knowing' or recognising the specificities of the individual carers and the caring relationships which they are in. Brannelly's (2011) consideration of the case of a 38 year old Pakistani woman with dementia and her family supports this. Colin needed, but felt deprived of, recognition of what he considered the distinctiveness of the spousal relationship and this appears to have contributed directly to his alienation from the course and his sense of being a 'nobody' which, in turn, meant that the information could not 'gel'. In contrast, for Lesley, the course came at exactly the right time; she felt recognised as someone struggling to feel confident in her current caring practices and she was able to identify with other carers and learn from their experiences and insights within a context where information and care were experienced as intertwined. Lesley flourished because she felt recognised - valued, welcome and 'very safe'. She was able to apply the information offered not only in terms of practical suggestions, but also as confirmation of her competence as a carer who was doing her best not only to do the right thing, but also to do it right. In the case of Pauline and Francis, the programme's focus on information for caregivers, rather than care receivers, appears to have exacerbated Francis' sense of powerlessness, an experience that has been articulated by many disabled people in relation to their carers. Informing with care in Pauline and Francis' case might result in calls for interventions that work with care receiver as well as caregiver, to better enable both to understand each other's response to their situation.

Our third point concerns the importance of understanding information as situated knowledge and how different types and combinations of knowledge are appropriate in different caring contexts- no 
two contexts are ever identical. Having the cognitive flexibility to recognise and practice with different knowledges, while being sensitive to questions of power, is key to informing with care. Lesley and Pauline, in particular, drew attention to the importance of the experiential knowledge of other carers on the course for helping make sense of the more propositional knowledge about the progress of dementia that was offered by course facilitators. Pauline acknowledged that she had heard much of what the course offered before but that 'hearing it again with other people' was especially important and that the people that did the course with her were 'as much value' as 'what was in the course'. Lesley's account similarly acknowledged the importance of the 'wonderful texts' but stressed that their value was determined by the extent to which they were able to convey the experiences of other carers. It was this experiential knowledge, coming from 'the heart', that helped her make use of the more factual knowledge about dementia and connect with others who really 'understand' in ways that could really support her care practices. This account illustrates well how Pols' 'know-now' involves working with different kinds of knowledge to enable 'living life with a disease' (Pols 2012, 87).

Finally, the particular context of this study enables us to reflect on the significance of the process of information sharing as well as the consequences of better information for care in practice if we are to inform with care. The CrISP programme was set up as both an information and support programme with the support generated by bringing carers together as well as being offered by course facilitators from the Alzheimer's Society. In many cases, this worked well and enabled precisely the kind of close connection between information and care we are advocating (see Authors et al 2013). However, we cannot assume that creating these shared spaces necessarily delivers support or enables carers to feel cared for. For information to enable care, the context within which this is shared needs to be experienced as 'caring' and our three cases demonstrate quite different experiences of this. Colin never found or experienced such support or care, but Lesley did and this impacted the benefit she derived from the information per se. Whereas Colin had struggled to trust the course tutor and the context provided, Lesley placed complete trust in both and was able to reap 
the benefits of what she experienced as a fully caring context. In the context of the complex personal issues facing Pauline in her relationship to Francis, and in the light of her long term and continuing activism in relation to disability issues, the course offered her a valuable space within which she could develop her understanding of dementia and use this not only in the context of her personal situation, but also in developing supports for others in a similar situation. However, these personal benefits came at a cost in terms of her relationship with Francis, something that went unacknowledged on the course.

\section{Conclusion}

We have drawn on an empirical study of an information and support programme for family carers of people with dementia (the CrISP course) to point to the limits of the 'inform to care' approach currently dominating policy and many practice settings. We have drawn on three cases of care relationships in that study to argue for a more situated, complex and contingent understanding of the relationship between information and care and for a practice that reflects this understanding- to 'inform with care'. Our argument reflects the importance of understanding care as an ethical, relational practice, rather than as a commodity that can be enhanced by better or more information. Our insights and arguments have implications beyond this study of dementia care. Informing with care can be developed as an ethical practice that means asking what happens to care and caring relationships whenever new information or knowledge is introduced in care contexts. It means asking what information does to care, as well as what care can do for information - understanding that how information is provided can be as important as its content. It also means ensuring that information and care don't become delinked, something that is especially important in contexts where health and social care information is increasingly being both digitised (provided 'at a distance' from, and outside the context of, caring relationships) and marketised, with private sector 
organisations playing ever greater roles in managing and delivering health and social care information.

\section{References}

Self citations to be added.

Alzheimer's Society. 2012. Support Services: Carer Information and Support Programme (CrISP), Service Specification. London: Alzheimer's Society.

Barker, P., Campbell, P. and Davidson, B.,eds. 1999.From the Ashes of Experience. Reflections on Madness, Survival and Growth. London:Whurr.

Brannelly, T. 2011 "That Others Matter: The Moral Achievement - Care Ethics and Citizenship in Practice with People with Dementia." Ethics and Social Welfare 5 (2):210-216.

Department of Health. 2009.Living Eell with Dementia: A National Dementia Strategy. London: Department of Health.

Department of Health. 2010. Healthy Lives, Healthy People: Our Strategy for Public Health in England. London: Department of Health.

Department of Health. 2012a The Power of Information: Putting Us All in Control of the Health and Care Information We Need. London: Department of Health.

Department of Health. 2012b. Caring for Our Future: Reforming Care and Support. London: Department of Health.

Haraway, D. 1991. "Situated knowledges: the science question in feminism and the privilege of partial perspective". In Simians, Cyborgs and Women, edited by D. Haraway, 183-201. New York: Routledge. 
Gilligan, C. 1982. In a Different Voice: Psychological Theory and Women's Development. Cambridge, MA: Harvard University Press.

Kittay, E. F. 2010. "The personal is philosophical is political: A philosopher and mother of a cognitively disabled person sends notes from the battlefield." In Cognitive Disability and its Challenge to Moral Philosophy, edited by E.F. Kittay and L. Carlson, 393-413. Chichester: Wiley-Blackwell.

Mol, A. 2008.The Logic of Care: Health and the Problem of Patient Choice. London: Routledge.

Molyneaux, V., S., Butchard, Simpson, J., and C. Murray.. 2011. "Reconsidering the term 'carer': a critique of the universal adoption of the term 'carer." Ageing and Society 31 (3): 422-437.

NHS Executive. 1998. Information for Health: An Information Strategy for the Modern NHS1998-2002. London: Department of Health.

Nettleton, S. 2004. "The emergence of E-scaped medicine." Sociology 38(4): 661-679.

Nussbaum, M. 2001.Upheavals of Thought: The Intelligence of the Emotions. Cambridge: Cambridge University Press.

Pettersen, T. \& M. H. Hem. 2011. “Mature care and reciprocity: Two cases from acute psychiatry.” Nursing Ethics 18(2): 217-231.

Pols, J. 2012.Care at a Distance: On the Closeness of Technology. Amsterdam: University of Amsterdam Press. 
Salander, P. \& R. Henriksson. 2005. "Severely diseased lung cancer patients narrate the importance of being included in a caring relationship." Lung Cancer, 50 (2):155-162.

Salander, P. and C. Moynihan. 2010. “Facilitating patients' hope work through relationship: a critique of the discourse of autonomy." In Configuring Health Consumers: Health Work and the Imperative of Personal Responsibility, edited by R. Harris, C.N. Wathen and S. Wyatt, 113-125. Basingstoke: Palgrave Macmillan.

Sevenhuijsen, S. 1998.Citizenship and the Ethics of Care: Feminist Considerations of Justice, Morality and Politics. London and New York, Routledge.

Sinding, C., P. Hudak, J.Wiernikowski, J. Aronson, J. Gould, and D. Fitzpatrick-Lewis. 2010. " ‘l like to be an informed person but...' :negotiating responsibility for treatment decisions in cancer care." Social Science and Medicine 71(6): 1094-1101.

Spoel, P. 2006. "Midwifery, consumerism and the ethics of informed choice."In Bordering Biomedicine, edited by V. Kalitzkus and P.L. Twohig, 197-213. Amsterdam: Rodopi.

Tronto, J.C. 1993.Moral Boundaries: A Political Argument for an Ethic of Care. New York and London: Routledge.

Ward, N. 2011. Care ethics and carers with learning disabilities: a challenge to dependence and paternalism, Ethics and Social Welfare, 5(2): 168-180. 